\title{
QUEEN'S
UNIVERSITY
BELFAST
}

\section{Interplay Between Sensation Seeking and Parental Rules in the Emergence of Heavy Episodic Drinking}

Percy, A., McKay, M. T., \& Cole, J. C. (2019). Interplay Between Sensation Seeking and Parental Rules in the Emergence of Heavy Episodic Drinking. Journal of Research On Adolescence, 29(4), 814-821.

https://doi.org/10.1111/jora.12435

Published in:

Journal of Research On Adolescence

Document Version:

Peer reviewed version

Queen's University Belfast - Research Portal:

Link to publication record in Queen's University Belfast Research Portal

Publisher rights

(c) 2018 Society for Research on Adolescence. This work is made available online in accordance with the publisher's policies. Please refer to any applicable terms of use of the publisher

\section{General rights}

Copyright for the publications made accessible via the Queen's University Belfast Research Portal is retained by the author(s) and / or other copyright owners and it is a condition of accessing these publications that users recognise and abide by the legal requirements associated with these rights.

Take down policy

The Research Portal is Queen's institutional repository that provides access to Queen's research output. Every effort has been made to ensure that content in the Research Portal does not infringe any person's rights, or applicable UK laws. If you discover content in the Research Portal that you believe breaches copyright or violates any law, please contact openaccess@qub.ac.uk. 
Interplay between sensation seeking and parental rules in the emergence of heavy episodic drinking

\author{
Andrew Percy, PhD. \\ Queen's University Belfast \\ Michael T. McKay, PhD. and Jon C. Cole, PhD. \\ University of Liverpool
}

\begin{abstract}
Author Note
Andrew Percy, Centre for Evidence and Social Innovation, School of Social Sciences, Education and Social Work, Queen's University Belfast.

Michael McKay, Department of Psychology, University of Liverpool.

Jon Cole, Department of Psychology, University of Liverpool.
\end{abstract}

Correspondence to: Dr Andrew Percy, Centre for Evidence and Social Innovation, School of Social Sciences, Education and Social Work, Queen's University Belfast, 6 College Park Belfast, Northern Ireland, BT7 1LP. a.percy@qub.ac.uk

This is a preprint of an article accepted for publication in Journal of Research on Adolescence. https://doi.org/10.1111/jora.12435. The full published article can be found at: https://onlinelibrary.wiley.com/doi/full/10.1111/jora.12435 


\begin{abstract}
This study examined the parallel mediational processes between sensation seeking and parental rules on alcohol, in the emergence of heavy episodic drinking (HED) in adolescents. Data were drawn from a UK clustered randomized control trial (control arm only, $\mathrm{N} \approx 6,300, M_{\text {age }}$ at baseline $=12.5$ ). Using parallel process latent growth curve analysis, stricter parental rules at baseline were found to be associated with greater declines in sensation seeking over time and a lower risk of HED at follow-up (+33 months). Higher initial levels of sensation seeking predicted a faster relaxation of parental rules and a greater risk of HED. By maintaining strict rules about alcohol, parents may promote a positive reduction in sensation seeking and a lower risk of HED.
\end{abstract}

Keywords: Sensation seeking; Parental rules on alcohol; Heavy episodic drinking; Parallel process latent growth curve analysis. 


\section{Interplay between sensation seeking and parental rules in the emergence of heavy episodic drinking}

From a dual systems perspective (e.g., Steinberg 2008; 2010) adolescent risk taking is thought to arise from an imbalance in the maturity rates of reward sensitivity and cognitive control systems, in which a heightened sensitivity to new sensations (peaking in adolescence) overpowers immature cognitive controls (peaking in early adulthood). Accordingly, adolescent alcohol use can be conceptualized as a failure of immature controls to counterbalance the desire for the hedonistic pleasure of intoxication (Percy, 2008). However, in addition to the regulatory control exerted by internal cognitive systems, contextual constraints, such as those imposed by parents, may play an important role in modifying risky behaviors (e.g., Shulman, et al, 2016).

Sensation seeking is broadly understood as the desire for intense and novel experiences (Zuckerman, 1994) and can be viewed as a psychological manifestation of an underlying neurobiological process comprising greater sensitivity to rewards and increased activation of the neural reward systems in the brain (Shulman et al., 2016). It has been shown to be a consistent predictor of adolescent alcohol use (e.g., Stautz, \& Cooper, 2013), as both sensation seeking and alcohol consumption increase significantly during early adolescence (Crawford, Pentz, Chou, Li, \& Dwyer, 2003; Collado, Felton, MacPherson, \& Lejuezet, 2014). Rapid increases in sensitivity to rewards during early adolescence appear to underpin the relationship between sensation seeking and teenage alcohol consumption (Castellanos-Ryan, Rubia, \& Conrod, 2011). As alcohol rewards can be both behavioral (such as the social value of consumption) and psychopharmacological (the pleasures of intoxication) in nature (see Conrod \& Nikolaou, 2016), sensation seeking appears to play a role in both the emergence of drinking (as a novel sensation) and the transition to binge/heavy drinking amongst adolescents (Stautz \& Cooper, 2013). Similarly, early onset alcohol consumption may inflate trajectories of sensation seeking behavior across adolescence (Charles et al., 2016), increasing sensitivity to alcohol rewards and the transition to heavy drinking patterns.

Parents can play an influential role in shaping adolescent drinking behaviors (Yap, Cheong, Zaravinos-Tsakos, Lubman, \& Jorm, 2017). Parental rules on alcohol have been shown to impact on 
both the onset of consumption and the transition into more problematic drinking (e.g., Koning, Eijnden, Verdurmen, Engels, \& Volleberghet, 2011; Van Der Vorst, Engels, Dekovic, Meeus, \& Vermulst, 2007). Parental rules on alcohol are a potential contextual constraint on adolescent sensation seeking that may arrest the development of drinking-related behaviors (Luciana, 2013). However, studies examining the association between parental rules, sensation seeking, and adolescent HED are relatively rare (see Sharmin et al., 2017). In an adolescent study, Janssen et al. (2014) reported significant main effects for both rules and sensation seeking on drinking, but no interaction effect. Similarly, Kaynak and colleagues (2013) found no interaction between sensation seeking and parental rules in the development of substance use in college students. However, in both studies parental rules and sensation seeking were modelled as time invariant covariates rather than as the dynamic processes they are known to be.

In the current study, we examine the interplay between sensation seeking (an index of reward sensitivity) and one possible external source of control (parental rules on alcohol) in the emergence of heavy episodic drinking (HED) in adolescents. We use a parallel process model to study the trajectories of both parental rules on alcohol and adolescent sensation seeking and their interrelationship. We predicted that higher sensation seeking (both initial status and growth rate) would be associated with a higher risk of HED (assessed at the final follow-up - T3), while stricter (higher) parental rules (both initial status and growth rate) would be associated with lower risk of HED. We further predicted that parental rules, as an external source of behavioral control, would reduce the influence of sensation seeking on HED.

\section{Methods}

Study design and participants

The study uses data from a cluster randomized controlled trial (RCT) examining the efficacy of an alcohol education intervention (McKay et al., 2018; Sumnall et al., 2017). Only those pupils randomized to the control group were included in this analysis because of the potential interaction between the intervention and key variables in the model. Participants $(N=6,358)$ were from 53 schools in Northern Ireland and Scotland. At the beginning of the study, participants were in their first year of High School $\left(M_{\mathrm{age}}=12.5\right.$ years $)$. Data were collected under examination-like conditions on 
school premises at baseline (T0) in June 2012 and at three follow-ups: +12 (T1), +24 (T2), and +33

(T3) months. By T3, the mean age of participants was just over 15. Opt in consent was obtained from school head-teachers/principals prior to randomization of the school to either intervention or control. Opt out consent from participants and their parents/guardians was obtained after randomization. Ethical consent was granted by the Research Ethics Committee of Liverpool John Moores University. A total of $39 \%(n=2,466)$ of the sample were from Scotland, $51 \%(n=3,269)$ were male, $23 \%(n=1258)$ were in receipt of free school meals (FSM; a proxy for low socioeconomic status), and $95 \%(n=4992)$ were white. By T3, 19\% $(n=1,199)$ of the sample were missing due to attrition. There was a higher rate of attrition for males $(19.8 \%, n=638)$, those in receipt of FSM $(25.9 \%, n=$ $375)$, and those who reported having used alcohol at baseline $(26.3 \%, n=426)$. A higher attrition rate was observed in Scotland $(23 \%, n=576)$ compared to NI $(16.0 \%, n=623)$.

Measures

The Brief Sensation Seeking Scale-4 (BSSS-4; Stephenson et al., 2003) was used to assess sensation seeking. Respondents were asked how strongly they agreed with four statements (e.g., "I would like to explore strange places"). A five-point Likert scale $(1=$ strongly disagree and $5=$ strongly agree) was averaged within subjects, creating a mean sensation seeking score.

The ten-item Rules about Alcohol Questionnaire (Van der Vorst, Engels, Meeus, Dekovic, \& Van Leeuwe, 2005) examines adolescents' perceptions of the rules and boundaries their parents place on their access to, and consumption of alcohol. Participants were asked about drinking situations ranging from being allowed to drink alcohol at home when a parent is around, to being allowed to come home drunk. Responses were scored on a five-point Likert scale $(1=$ completely acceptable; $5=$ completely unacceptable) with higher scores indicating stricter rules. Scores were averaged within subjects, creating a mean parental rules score.

At T3 (+33 months) respondents were asked to report their past 30-days frequency of HED (never/once/twice/3 times/4-5times/6-7times/8 or more times). For males, HED corresponded to consumption of six or more units of alcohol, for females, the threshold was 4.5 units of alcohol. This frequency count was dichotomized at never/one or more occasion. To aid the accuracy of recall, respondents were presented with pictorial images of how much alcohol $\geq 6 / \geq 4.5$ UK units represented. 
For example, one image for boys comprised 6 small bottles of a popular alcopop, another showed a $20 \mathrm{cl}(1 / 4)$ bottle of vodka.

A slightly different indicator of HED was employed at T0 (baseline). Here, respondents were asked about the frequency of consuming 5 or more drinks in the last month, which was dichotomized for the purpose of this study. However, as the term 'drink' could refer to drinks of different alcohol strength and volume the decision was taken to change the HED measure to UK units of alcohol (10ml/8g of alcohol) for T3. This change was implemented before the final wave of data collection, and analyses of study outcome measures at any data collection point had been undertaken.

Respondents' gender was included as dichotomous covariate.

Analysis

We used a parallel process latent growth curve model (LGCM) to examine the developmental changes in sensation seeking and parental rules on alcohol, the interplay between sensation seeking and parental rules, and their reciprocal influence on HED (see for example, Crawford, et al., 2003). Parallel process LGCMs estimate individual differences in the initial status of respondents (random intercepts) and individual differences in the rate of change over time (random slopes/growth rates) on both variables under examination (see Figure 1).

The effect of the initial status of sensation seeking on the growth rate of parental rules and the initial status of parental rules on the growth rate of sensation seeking were also modelled. HED (T3) was regressed on sensation seeking and rules (both initial status and growth rate), as well as the covariates, namely gender and baseline HED (T0). The parallel process parameters (initial status and growth rate) were regressed on gender to assess gender specific differences in the trajectories of sensation seeking and parental rules. Only the growth rates (and not initial status) for both sensation seeking and parental rules were regressed on baseline drinking, as the dual systems model would suggest that earlier (unobserved) levels of sensation seeking and parental rules would determine baseline drinking levels rather than baseline drinking influencing the initial status of either sensation seeking or rules.

All models were estimated in Mplus 7.3 (Muthén \& Muthén, 1998-2012). The factor loadings for the initial status latent variables were constrained to zero for all time points. Given the unequal 
time gaps in data collection, the factor loadings for the latent growth rates were constrained to $\mathrm{T} 0=0$, $\mathrm{T} 1=1, \mathrm{~T} 2=2, \mathrm{~T} 3=2.75$. A maximum likelihood estimator with robust standard errors (MLR) was used to estimate standard errors robust to the clustered nature of the sample. Missing data were handled using standard Mplus FIML procedures. In the full model, 849 cases were missing on one or more of the $\mathrm{X}$ variables and were excluded from the analysis, giving an achieved sample size for the estimated model of 5,509. Numerical integration with 400 integration points was employed to estimate the final model.

[Figure 1 about here]

\section{Results}

Table 1 displays the descriptive statistics for the parallel processes, model covariates, and HED. Overall, a slight increase was observed in sensation seeking between T0 and T2 (ages 12.5 to 14.5), which levelled off by T3 (age 15.3). In contrast, a slight decrease was observed in the means for parental rules on alcohol between T0 (4.6) and T3 (4.3). At T0, around eight per cent reported at least one episode of HED in the past 30 days. By T3 this had increased to over $25 \%$.

[Table 1 about here]

Separate unconditional LGCMs were estimated for sensation seeking, parental rules, and the combined parallel processes. The fit for the sensation seeking model $\left(\chi^{2}[5,6,356]=12.062, p=\right.$ 0.034; RMSEA $=0.015 ; \mathrm{CFI}=0.996)$, the parental rules model $((\chi 2[5,6,356]=199.66, p<0.0001$; RMSEA $=0.078 ; C F I=0.986)$, and the unconditional parallel process model $((\chi 2[24,6,357]=$ $390.459, p<0.0001 ; \mathrm{RMSEA}=0.049 ; \mathrm{CFI}=0.968)$, were all acceptable. Given the nature of the final conditional model estimated (Fig 1), traditional SEM fit indices were not available.

[Table 2 about here]

Table 2 displays the initial status and growth rate parameters in the parallel process LGCM. Sensation seeking shows a flat rate of growth over the study period (0.02). In contrast, the strictness of rules declines slightly with age $(-0.11)$.

[Table 3 about here]

Table 3 provides the model regression parameter estimates for the covariates gender (on the initial statues and growth rates) and baseline HED (on growth rates), the mediation processes, and the 
HED outcomes. Females reported lower initial levels of sensation seeking, but a greater developmental increase in sensation seeking over time relative to males (as evidenced by the positive parameter estimate when the sensation seeking growth rate is regressed on gender). The sensation seeking trajectory for males was relatively flat. For parental rules on alcohol, females report a higher initial level than males (i.e. stricter rules), but a faster rate of relaxation in parental strictness (i.e. greater increase in leniency) over time.

Stricter parental rules at T0 (initial status) were associated with reduction in the growth rate of sensation seeking over the study period $(b=-0.07, \mathrm{p}=<0.001)$. In a similar way, a higher level of sensation seeking at T0 was associated with a more rapid decline in parental rules scores $(b=-0.08, \mathrm{p}$ $=<0.001)$. As initial sensation seeking increased, the rate of decline in parental rules became more pronounced (it fell faster). Similarly, early onset HED (at T0) appeared to impact on the age-related relaxation of parental rules (i.e. speeding it up; $b=-0.11, \mathrm{p}=<0.001$ ), but HED at T0 did not appear to alter the developmental trajectory of sensation seeking $(b=-0.007, \mathrm{p}=0.592)$.

While higher levels of sensation seeking at $\mathrm{T} 0$ were associated with an increased risk of HED at T3 $(b=0.67, \mathrm{p}=<0.001)$, higher levels of parental rules at T0 reduced that risk $(b=-1.35, \mathrm{p}=$ $<0.001)$. A higher growth rate in sensation seeking was associated with a higher log odds of HED at T3 $(b=8.12, \mathrm{p}=<0.001)$. The reverse was true for parental rules, where a less negative growth rate (a slower decline) predicted a lower log odds of HED at T3 $(b=-6.73, \mathrm{p}=<0.001)$.

\section{Discussion}

The present study set out to model the parallel trajectories of parental rules on alcohol and adolescent sensation seeking, to assess the impact of an external environmental constraint (parental rules) on the developmental course of reward sensitivity (sensation seeking), a core component of the dual systems model of adolescent risk taking, and to investigate how these parallel mediational processes of sensation seeking and parental rules were associated with the emergence of heavy episodic drinking (HED). In summary, the findings suggested that sensation seeking was rather stable over time amongst boys, while it increased slightly amongst girls across the four sweeps of data collection. Parental rules on alcohol, in contrast, become more lenient as the young people grew older. Having a higher initial level of sensation seeking or increases in sensation seeking behaviors over 
time, predicted an increased risk of HED, confirming earlier work on this area (Stautz, \& Cooper, 2013). In contrast, having and maintaining stricter parental rules about drinking significantly predicted lower engagement in HED (Yap et al., 2017).

Important parallel mediational processes between parental rules and self-reported sensation seeking were also observed. Strict parental rules restricted the growth rate of sensation seeking across early adolescence. This suggests that the trajectories of psychological traits such as sensation seeking, and their underlying neurological processes, may be amenable to external influences altering their developmental course. Parental behaviors may promote the maturation of reward sensitivity, sensation seeking, and risk taking behaviors by possibly denying access to risk taking opportunities at a young age, or by potentially channeling sensation seeking towards more pro-social rewards. Recent studies have found that neighborhood disadvantage moderates the relationship between sensation seeking and substance use largely via the provision of additional risk taking opportunities (Burdzovic Andreas \& Watson, 2016; Jensen, Chassin and Gonzales, 2017). In contrast to this research, it should be noted that most studies that have examined the relationship between sensation seeking and parental behaviors have failed to find a significant interaction (e.g. Janssen et al., 2014; Kaynak et al., 2013). However, this is the first study to model both sensation seeking and parental behaviors as dynamic rather than static constructs, and to examine the impact of parenting behaviors on the developmental trajectory of sensation seeking through mediational processes rather than moderation effects.

Similarly, adolescent sensation seeking appears to alter the course of parental rule setting. For children with high reward sensitivity, the expectation would be for parents to impose stricter external controls on access to high-risk activities to counter the child's heightened internal drive to engage in such activities. However, the opposite seemed to occur, with parents whose children reported higher levels of sensation seeking appearing to relax alcohol rules at a faster rate, which suggests that the parents potentially share the same levels of sensation seeking and thus tolerate this behavior at what they consider to be an appropriate age (most likely the age that they drank underage). Teenagers see the alcohol rules set by parents as a movable boundary against which they are expected to push, in the hope of prompting ever more lenient controls as they grow older (Percy, Wilson, McCartan \& McCrystal, 2011). Adolescents with higher levels of sensation seeking may indulge in these boundary 
disputes with a greater frequency or with greater success than their less reward sensitive peers inducing a relaxation of the rules. Alternatively, parents of high sensation seeking children may choose their 'battles' carefully. A slight relaxation of rules surrounding alcohol consumption, permitting access to a perceived lower risk activity, may be seen as a way of protecting and maintaining rules on higher risk activities (e.g. illicit drug use). It may also be the case that higher sensation seeking adolescents are more sensitive to any relaxation of parental boundaries or constraints (see Slagt et al. 2016), and the potential rewards that this exposes, rating their parents as less strict than their lower sensation seeking peers.

While having no effect on the development of sensation seeking, early onset drinking predicted greater leniency amongst parents regarding their child's access to alcohol, further escalating the child's risk of HED in middle adolescence. Early onset drinking (stimulated by high reward sensitivity) may create a cascade effect through which parents become more lenient in their rules regarding alcohol, thereby increasing opportunities to drink and socialize with other teens (see Kim et al., 2017), maintaining higher levels of sensation seeking and increasing the risks of later adolescent HED (see Fergusson, Lynskey, \& Horwood, 1994).

The study confirms sex differences in the developmental trajectory of sensation seeking and parental rules. However, it challenges prior research that suggests sensation seeking peaks earlier in girls than boys (e.g. Shulman, Harden, Chein \& Steinberg, 2015). The relatively brevity of the followup in this study (up to age 15) may have censured later fluctuation in sensation seeking behavior (see for example, Littlefield Stevens, Ellingson, King, \& Jackson, 2016). Interestingly, girls appear to experience stricter alcohol rules whilst having lower levels of sensation seeking than boys. This may reflect increased parental concerns regarding teenage boys and alcohol. Koning and colleagues (2013) found that parents worried more about teenage sons than daughters, yet parental worries predicted less restrictive rule setting, a lower quality of communication between parent-child dyads and higher teenage drinking.

The study is not without limitations. Firstly, the study is based on self-report and as a result there may be a degree of measurement error associated with the reporting of alcohol consumption. Similarly, levels of sensation seeking may bias the reporting of parental alcohol rules. An independent 
measure of rules would have been preferable. While it can be argued that the parental rules questionnaire only assesses children's perceptions of parental rules, as opposed to how parents actually define their rules, adolescent perceptions of parental alcohol rules may be more influential on their drinking than the rules as reported by the parents (Koning, Eijnden, Engels, Verdurmen, \& Vollebergh, 2011). Also, parental reports of alcohol rules may be subject to greater social desirability pressures than adolescent reports (Kypri, Dean, Kirby, Harris, \& Kake, 2005).

Despite these limitations, the findings may have implications for social policy in this area. It appears that, in an environment where parents often feel helpless regarding their ability to impact on adolescent risk-taking, strict parental rules may contribute to a reduction in HED, both directly and indirectly via reduced sensation seeking. Prevention interventions that include a parental component aimed at fostering strict parental rules may be a way of promoting a shift in parental rule setting and reducing HED (see for example, McKay et al., 2018; Sumnall et al., 2017, Koning et al., 2011).

\section{References}

Burdzovic Andreas, J., \& Watson, M. W. (2016). Person-environment interactions and adolescent substance use: the role of sensation seeking and perceived neighborhood risk. Journal of Child \& Adolescent Substance Abuse, 25, 438-447.

Castellanos-Ryan, N., Rubia, K., \& Conrod, P. J. (2011). Response inhibition and reward response bias mediate the predictive relationships between impulsivity and sensation seeking and common and unique variance in conduct disorder and substance misuse. Alcoholism: Clinical and Experimental Research, 35, 140-155.

Charles, N. E., Ryan, S. R., Bray, B. C., Mathias, C. W., Acheson, A., \& Dougherty, D. M. (2016). Altered developmental trajectories for impulsivity and sensation seeking among adolescent substance users. Addictive Behaviors, 60, 235-241.

Collado, A., Felton, J. W., MacPherson, L., \& Lejuez, C. W. (2014). Longitudinal trajectories of sensation seeking, risk taking propensity, and impulsivity across early to middle adolescence. Addictive Behaviors, 39, 1580-1588. 


\section{SENSATION SEEKING AND PARENTAL RULES}

Conrod, P., \& Nikolaou, K. (2016). Annual Research Review: On the developmental neuropsychology of substance use disorders. Journal of Child Psychology and Psychiatry, 57, 371-394.

Crawford, A. M., Pentz, M. A., Chou, C. P., Li, C., \& Dwyer, J. H. (2003). Parallel developmental trajectories of sensation seeking and regular substance use in adolescents. Psychology of Addictive Behaviors, 17, 179.

Fergusson, D. M., Lynskey, M. T., \& Horwood, L. (1994). Childhood exposure to alcohol and adolescent drinking patterns. Addiction, 89, 1007-1016.

Janssen, T., Larsen, H., Peeters, M., Pronk, T., Vollebergh, W.A.M., \& Weirs, R.W. (2014). Interactions between Parental Alcohol-Specific Rules and Risk Personalities in the Prediction of Adolescent Alcohol Use. Alcohol and Alcoholism, 49, 579-585.

Jensen, M., Chassin, L., \& Gonzales, N. A. (2017). Neighbourhood moderation of sensation seeking effects on adolescent substance use initiation. Journal of Youth and Adolescence, 46, 1953-1967.

Kaynak, Ö., Meyers, K., Caldeira, K. M., Vincent, K. B., Winters, K. C., \& Arria, A. M. (2013). Relationships among parental monitoring and sensation seeking on the development of substance use disorder among college students. Addictive Behaviors, 38, 1457-1463.

Kim, M. J., Mason, W. A., Herrenkohl, T. I., Catalano, R. F., Toumbourou, J. W., \& Hemphill, S. A. (2017). Influence of early onset of alcohol use on the development of adolescent alcohol problems: a longitudinal binational study. Prevention Science, 18, 1-11.

Koning, I. M., Eijnden, R. J. J. M. v. d., Engels, R. C. M. E., Verdurmen, J. E. E., \& Vollebergh, W. A. M. (2011). Why target early adolescents and parents in alcohol prevention? The mediating effects of self-control, rules and attitudes about alcohol use. Addiction, 106(3), 538-546.

Koning, I. M., Eijnden, R. J. v. d., Glatz, T., \& Vollebergh, W. A. (2013). Don't worry! Parental worries, alcohol-specific parenting and adolescents' drinking. Cognitive Therapy and Research, 37(5), 1079-1088. https://doi.org/10.1007/s10608-013-9545-0. 


\section{SENSATION SEEKING AND PARENTAL RULES}

Koning I.M., Eijnden, R. J. J. M. v. d., Verdurmen J.E., Engels, R.C.M.E., \& Vollebergh, W. A. (2011). Long-term effects of a parent and student intervention on alcohol use in adolescents: a cluster randomized controlled trial. American Journal of Preventative Medicine, 40, 541-547.

Kypri, K., Dean, J., Kirby, S., Harris, J., \& Kake, T. A. I. (2005). 'Think before you buy under-18s drink': evaluation of a community alcohol intervention. Drug and Alcohol Review, 24(1), 13-20.

Littlefield, A.K., Stevens, A.K., Ellingson, J.M., King, K.M., \& Jackson, K.M. (2016). Changes in negative urgency, and sensation seeking across adolescence. Personality and Individual Differences, 90, 332-337.

Luciana, M. (2013). Adolescent brain development in normality and psychopathology. Development and Psychopathology, 25, 1325-1345.

McKay, M., Agus, A., Cole, J., Doherty, P., Foxcroft, D., Harvey, S., Murphy, L., Percy, A. \& Sumnall, H. (2018). Steps Towards Alcohol Misuse Prevention Programme (STAMPP): a school-based and community-based cluster randomised controlled trial. BMJ open, 8, e019722. doi: 10.1136/bmjopen-2017-019722.

Muthén, L.K. and Muthén, B.O. (1998-2012). Mplus User’s Guide. Seventh Edition. Los Angeles, CA: Muthén \& Muthén

Percy, A. (2008). Moderate adolescent drug use and the development of substance use selfregulation. International Journal of Behavioral Development, 32, 451-458.

Percy, A., Wilson, J., McCartan, C., McCrystal, P. (2011). Teenage drinking cultures. York UK: Joseph Rowntree Foundation. https://www.jrf.org.uk/file/40894/download?token=O9dodIKY\& filetype=full-report

Sharmin, S., Kypri, K., Khanam, M., Wadolowski, M., Bruno, R., Attia, J., Holliday, E., Palazzi, K. \& Mattick, R. P. (2017). Effects of parental alcohol rules on risky drinking and related problems in adolescence: Systematic review and meta-analysis. Drug and Alcohol Dependence, 178, 243256. 


\section{SENSATION SEEKING AND PARENTAL RULES}

Shulman, E. P., Smith, A. R., Silva, K., Icenogle, G., Duell, N., Chein, J., \& Steinberg, L. (2016). The dual systems model: Review, reappraisal, and reaffirmation. Developmental Cognitive Neuroscience, 17, 103-117.

Shulman, E.P., Harden, K.P., Chein, J.M. \& Steinberg, L. (2015). Sex differences in the developmental trajectories of impulse control and sensation-seeking from early adolescence to early adulthood. Journal of Youth and Adolescence. 44, 1-17.

Slagt, M., Dubas, J. S., Deković, M., \& van Aken, M. A. G. (2016). Differences in sensitivity to parenting depending on child temperament: A meta-analysis. Psychological Bulletin, 142(10), 1068-1110. http://dx.doi.org/10.1037/bul0000061

Stautz, K., \& Cooper, A. (2013). Impulsivity-related personality traits and adolescent alcohol use: a meta-analytic review. Clinical Psychology Review, 33, 574-592.

Steinberg, L. (2008). A social neuroscience perspective on adolescent risk-taking. Developmental Review. 28, 78-106.

Steinberg, L. (2010). A dual systems model of adolescent risk-taking. Developmental Psychobiology, 52, 216-224.

Stephenson, M. T., Hoyle, R. H., Palmgreen, P., \& Slater, M. D. (2003). Brief measures of sensation seeking for screening and large-scale surveys. Drug and Alcohol Dependence, 72, 279286.

Sumnall, H., Agus, A., Cole, J., Doherty, P., Foxcroft, D., Harvey, S., McKay, M., Murphy, L. \& Percy, A. (2017). Steps towards alcohol misuse prevention programme (STAMPP): A school-and community-based cluster randomised controlled trial. Public Health Research, 5(2), 1-154.

Van der Vorst, H., Engels, R. C. M. E., Dekovic, M., Meeus, W., \& Vermulst, A. A. (2007). Alcohol-specific rules, personality and adolescents' alcohol use: A longitudinal person environment study. Addiction, 102, 1064-1075.

Van der Vorst, H., Engels, R. C. M. E., Meeus, W., Dekovic, M., \& Van Leeuwe, J. (2005). The role of alcohol-specific socialization in adolescents' drinking behaviour. Addiction, 100, 1464-1476. 
Yap, M. B., Cheong, T. W., Zaravinos-Tsakos, F., Lubman, D. I., \& Jorm, A. F. (2017). Modifiable parenting factors associated with adolescent alcohol misuse: A systematic review and metaanalysis of longitudinal studies. Addiction, 112: 1142-1162.

Zuckerman, M. (1994). Behavioral Expression and Biosocial Bases of Sensation Seeking. Cambridge University Press, New York. 
Table 1: Variance-covariate matrix for the parallel processes (sensation seeking and parental rules), covariates and distal outcome

\begin{tabular}{|c|c|c|c|c|c|c|c|c|c|c|c|}
\hline & $\begin{array}{c}\text { Sen Seek } \\
\text { T0 }\end{array}$ & $\begin{array}{c}\text { Sen Seek } \\
\text { T1 }\end{array}$ & $\begin{array}{c}\text { Sen Seek } \\
\text { T2 }\end{array}$ & $\begin{array}{c}\text { Sen Seek } \\
\text { T3 }\end{array}$ & $\begin{array}{c}\text { Rules } \\
\text { T0 }\end{array}$ & $\begin{array}{c}\text { Rules } \\
\text { T1 }\end{array}$ & $\begin{array}{c}\text { Rules } \\
\text { T2 }\end{array}$ & $\begin{array}{c}\text { Rule } \\
\text { T3 }\end{array}$ & $\begin{array}{c}\text { Gender } \\
\text { (F) }\end{array}$ & $\begin{array}{c}\text { Binge } \\
\text { drinking } \\
\text { T3 }\end{array}$ & $\begin{array}{c}\text { Binge } \\
\text { drinking } \\
\text { T0 }\end{array}$ \\
\hline Sen Seek T0 & 0.799 & & & & & & & & & & \\
\hline Sen Seek T1 & 0.387 & 0.773 & & & & & & & & & \\
\hline Sen Seek T2 & 0.332 & 0.400 & 0.683 & & & & & & & & \\
\hline Sen Seek T3 & 0.280 & 0.365 & 0.396 & 0.698 & & & & & & & \\
\hline Rules T0 & -0.130 & -0.091 & -0.067 & -0.070 & 0.379 & & & & & & \\
\hline Rules T1 & -0.091 & -0.115 & -0.077 & -0.088 & 0.176 & 0.393 & & & & & \\
\hline Rules T2 & -0.087 & -0.093 & -0.115 & -0.105 & 0.219 & 0.237 & 0.549 & & & & \\
\hline Rules T3 & -0.108 & -0.121 & -0.124 & -0.150 & 0.270 & 0.254 & 0.431 & 0.727 & & & \\
\hline Gender $(F)$ & -0.085 & -0.070 & -0.042 & -0.036 & 0.033 & 0.014 & 0.016 & 0.014 & 0.250 & & \\
\hline Binge drinking $\mathrm{T} 3$ & -0.054 & 0.077 & 0.079 & 0.093 & -0.073 & -0.086 & -0.119 & -0.168 & 0.012 & 0.193 & \\
\hline Binge drinking T0 & 0.034 & 0.025 & 0.019 & 0.017 & -0.066 & -0.047 & -0.046 & -0.054 & -0.006 & 0.027 & 0.073 \\
\hline Means $/ \%$ (All) & 3.556 & 3.581 & 3.608 & 3.591 & 4.572 & 4.564 & 4.438 & 4.250 & $48.49 \%$ & $25.63 \%$ & $7.83 \%$ \\
\hline Means/\% (Male) & 3.721 & 3.721 & 3.693 & 3.661 & 4.508 & 4.533 & 4.405 & 4.218 & - & $23.35 \%$ & $8.84 \%$ \\
\hline Means $/ \%$ (Female) & 3.383 & 3.435 & 3.516 & 3.518 & 4.640 & 4.597 & 4.472 & 4.284 & - & $27.97 \%$ & $6.72 \%$ \\
\hline
\end{tabular}

Notes: Sen Seek $=$ Sensation Seeking, Rules $=$ Parental Rules on Alcohol, $F=$ Female. 
Table 2: Model initial status and growth rate parameters in the parallel processes LGCM

\begin{tabular}{lrrc}
\hline & $\begin{array}{l}\text { Initial } \\
\text { status }\end{array}$ & \multicolumn{1}{c}{$\begin{array}{l}\text { Growth } \\
\text { rate }\end{array}$} & $\begin{array}{c}\text { Residual } \\
\text { variance }\end{array}$ \\
\hline Sensation seeking T0 & 1.00 & 0.00 & 0.47 \\
Sensation seeking T1 & 1.00 & 1.00 & 0.38 \\
Sensation seeking T2 & 1.00 & 2.00 & 0.29 \\
Sensation seeking T3 & 1.00 & 2.75 & 0.31 \\
Intercepts - sensation seeking & 3.72 & 0.31 & - \\
Means - sensation seeking & 3.36 & 0.02 & - \\
Parental alcohol rules T0 & 1.00 & 0.00 & 0.20 \\
Parental alcohol rules T1 & 1.00 & 1.00 & 0.21 \\
Parental alcohol rules T2 & 1.00 & 2.00 & 0.22 \\
Parental alcohol rules T3 & 1.00 & 2.75 & 0.27 \\
Intercepts - rules & 4.57 & 0.22 & - \\
Means - rules & 4.63 & -0.11 & - \\
\hline
\end{tabular}


Table 3: Parameter estimates for the covariates, mediation processes and distal outcome in the parallel process LGCM

\begin{tabular}{lrrr}
\hline & Est & SE & $\mathrm{p}$ \\
\hline Gender $(\mathrm{F}) \rightarrow$ Initial status (Sen Seek) & -0.345 & 0.036 & $<0.001$ \\
Gender $(\mathrm{F}) \rightarrow$ Initial status (Rules) & 0.114 & 0.033 & $<0.001$ \\
Gender (F) $\rightarrow$ Growth rate (Sen Seek) & 0.086 & 0.012 & $<0.001$ \\
Gender $(\mathrm{F}) \rightarrow$ Growth rate (Rules) & -0.063 & 0.013 & $<0.001$ \\
Initial status (Rules) $\rightarrow$ Growth rate (Sen Seek) & -0.072 & 0.013 & $<0.001$ \\
Initial status (Sen Seek) $\rightarrow$ Growth rate (Rules) & -0.080 & 0.009 & $<0.001$ \\
Binge drinking T0 $\rightarrow$ Growth rate (Sen seek) & -0.007 & 0.013 & 0.592 \\
Binge drinking T0 $\rightarrow$ Growth rate (Rules) & -0.105 & 0.019 & $<0.001$ \\
Initial status (Rules) $\rightarrow$ Binge drinking T3 & -1.345 & 0.191 & $<0.001$ \\
Initial status (Sen Seek) $\rightarrow$ Binge drinking T3 & 0.670 & 0.098 & $<0.001$ \\
Growth rate (Rules) $\rightarrow$ Binge drinking T3 & -6.732 & 0.724 & $<0.001$ \\
Growth rate (Sen Seek) $\rightarrow$ Binge drinking T3 & 8.115 & 1.304 & $<0.001$ \\
Binge drinking T0 $\rightarrow$ Binge drinking T3 & 0.945 & 0.195 & $<0.001$ \\
\hline
\end{tabular}

Notes: $\mathrm{F}=$ female (male is the corresponding reference category), Sen Seek $=$ sensation seeking, Rules $=$ parental rules on alcohol. 
Fig 1: Parallel Process Latent Growth Curve Model

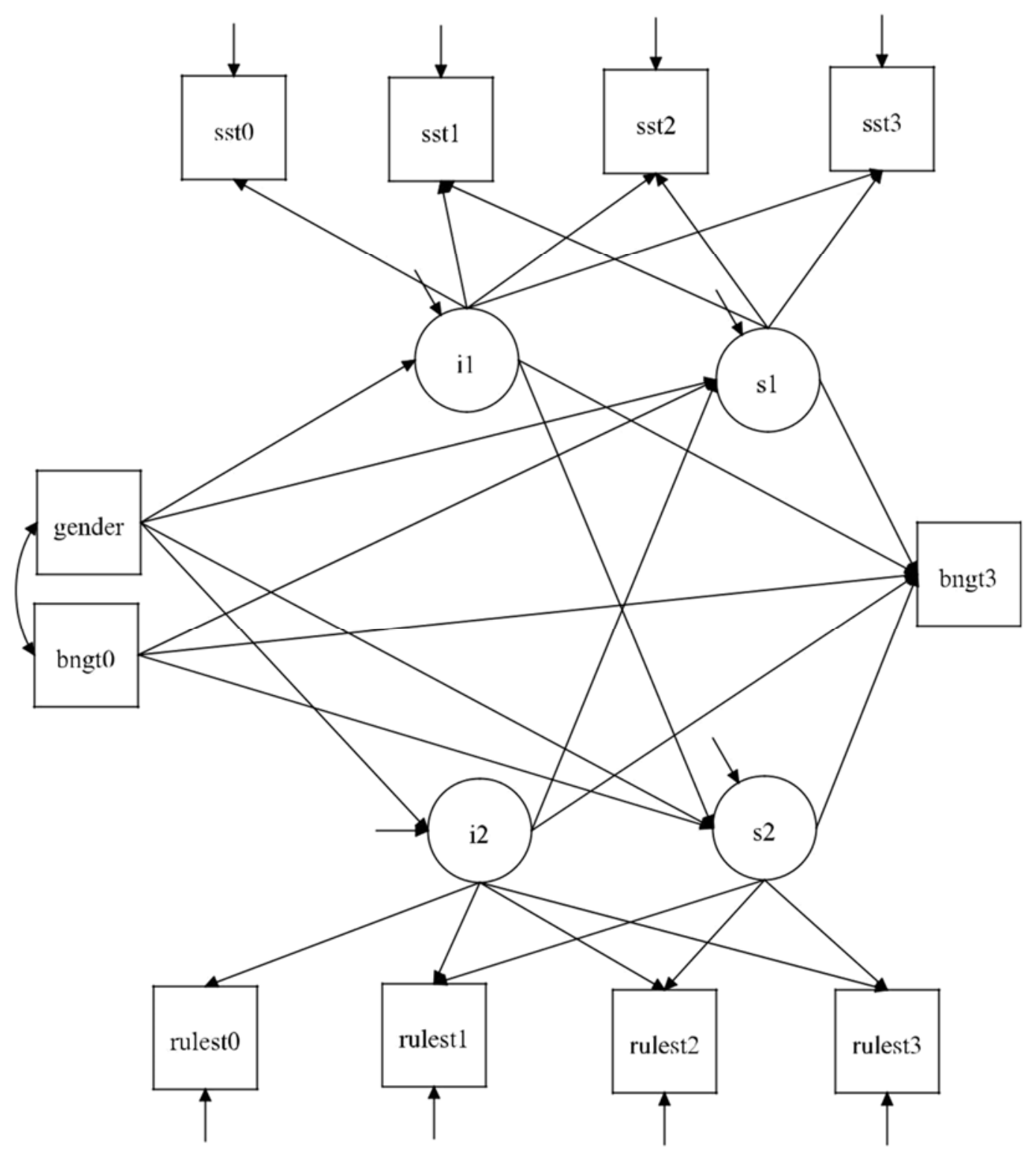

Notes: $\mathrm{ss}=$ sensation seeking; rules $=$ parental rules on alcohol;

$\mathrm{t} 0=$ baseline; $\mathrm{t} 1=12$ months follow-up; $\mathrm{t} 2=24$ months follow-up;

t3 = 33 months follow-up; bng = heavy episodic drinking;

$\mathrm{i}=$ intercepts; $\mathrm{s}=$ slopes. 